\title{
Visualisasi Berbasis Naive Bayes untuk Pemetaan Penyebaran Penyakit Infeksi Saluran Pernafasan Akut
}

\section{Naive Bayes Based Visualization For Mapping Acute Respiratory Infection Disease}

\author{
Yoga Prasetio $^{1}$, Hanny Haryanto ${ }^{2}$ \\ ${ }^{1,2}$ Jurusan Teknik Informatika, Fakultas Ilmu Komputer, \\ Universitas Dian Nuswantoro Semarang, \\ Jln. Nakula 1 No 5-11 Semarang 50131 \\ 1111201005633@mhs.dinus.ac.id, ${ }^{2}$ hanny_haryanto@dsn.dinus.ac.id
}

\begin{abstract}
Abstrak
Di daerah yang terjadi banyak kasus penyakit Infeksi Saluran Pernafasan Akut (ISPA), data-data yang telah terkumpul tidak digunakan dengan maksimal dan hanya digunakan untuk kebutuhan operasional. Padahal dengan adanya proses klasifikasi yang benar akan membantu dalam menemukan pola pembeda kelas dan membantu prediksi pola agar mempermudah dan tepat sasaran sesuai dengan Program Pemberantasan ISPA. Masyarakat pun dapat mengetahui tentang apa itu ISPA dan meningkatkan kewaspadaan terhadap penyebaran penyakit ISPA sehingga membentuk masyarakat tanggap ISPA. Klasifikasi secara otomatis dapat dilakukan menggunakan kecerdasan buatan, salah satunya dengan metode Naive Bayes. Naive bayes adalah metode yang melakukan proses klasifikasi berdasarkan teorema bayes. Metode diterapkan dalam data penyakit ISPA dan melakukan klasifikasi berdasarkan data tersebut. Dengan demikian, informasi visual tentang penyebaran penyakit ISPA dapat disajikan lebih detail sehingga membentuk masyarakat tanggap ISPA dan membantu pihak medis untuk menyelesaikan target pemberantasan penyakit ISPA P2 dari Dinas Kesehatan. Hasil dari penelitian ini adalah visualisasi yang digunakan untuk pemetaan penyebaran penyakit infeksi saluran pernafasan akut berbasis klasifikasi menggunakan Naive Bayes.
\end{abstract}

Kata kunci-ISPA, Naive Bayes, GIS, Pneoumonia

\begin{abstract}
In areas that have been many cases of Acute Respiratory Infections (ARI), the data that has been collected is not used to the maximum, and only used for operational needs. Whereas the presence of the correct classification process will assist in finding the pattern of distinguishing classes and assist in predicting the pattern in order to simplify and targeted according to ISPA Eradication Program. The community can find out what it is about ISPA and increasing vigilance against the spread of respiratory diseases that make up the ARD aware community. Classification can be done automatically using artificial intelligence, one of them with a Naive Bayes methods. Naive Bayes is a method of conducting the process of classification based on Bayes theorem. Methods applied in the data ARI and perform classification based on that data. Thus, visual information about the spread of respiratory diseases can be presented in more detail so as to shape society ARD response and help the medical side to complete the target of disease eradication P2 ISPA Department of Health. The results of this research was the visualization that is used for mapping the spread of acute respiratory tract infections based classification using Naive Bayes.
\end{abstract}

Keywords - ARI, Naive Bayes, GIS, Pneumonia

74 Jurnal Ilmiah SISFOTENIKA 


\section{PENDAHULUAN}

Infeksi Saluran Pernapasan Akut (ISPA) adalah masalah utama mortalitas pada kasus balita di negara Indonesia setelah diare yang mencapai angka 13,2\% berdasarkan Riskesdas 2007[1]. ISPA adalah sebuah infeksi akut yang menyerang salah satu bagian atau lebih dari saluran napas mulai hidung hingga alveoli termasuk adneksanya seperti sinus, rongga telinga tengah, pleura[2]. ISPA, secara anatomis terbagi menjadi dua bagian yaitu atas seperti batuk pilek, sakit telinga (otitis media), radang tenggorokan (faringitis) dan bawah yaitu bronchitis, bronkhiolitis dan pneumonia[3]. Berdasarkan P2 ISPA, penyakit ISPA dikategorikan dalam dua golongan yaitu pneumonia dan yang bukan pneumonia [4]. Sedangkan penyakit pneumonia sendiri dibedakan berdasarkan atas derajat beratnya penyakit yaitu pneumonia berat dan pneumonia ringan. Bukan pneumonia terdiri dari batuk pilek seperti rinitis, faringitis, tonsillitiss dan penyakit jalan napas bagian atas lainnya. Banyak sekali faktor yang dapat mempengaruhi penularan ISPA, akan tetapi faktor resiko yang paling banyak menyebabkan penyakit ISPA adalah sosio-ekonomi (pendapatan keluarga, perumahan, sanitasi dan pendidikan orangtua), status gizi, tingkat pengetahuan sebuah keluarga dan faktor lingkungan (kualitas udara) [5] infeksi saluran pernapasan akut (ISPA) tidak terkecuali. Penyebab utama ISPA adalah lingkungan yang ditularkan melalui droplet dan kontak (termasuk kontaminasi tangan yang diikuti oleh inokulasi tak sengaja) dan aerosol pernapasan infeksius berbagai ukuran dan dalam jarak dekat, misalnya keberadaan pabrik yang dekat pemukiman atau adanya perokok dalam satu rumah[6]. Di daerah Kaliwungu terjadi banyak sekali kasus ISPA [7] sedangkan pada puskesmas Kaliwungu tepatnya di Kecamatan Kaliwungu penderita penyakit ISPA mencapai mencapai angka 400 pasien lebih per tahunnya (data dari Puskesmas Kaliwungu) kemudian data-data yang telah sudah terkumpul hanya menjadi "kuburan data" saja, digunakan untuk kebutuhan operasional. Padahal dengan adanya proses klasifikasi yang benar akan membantu dalam menemukan pola pembeda kelas dan membantu pemprediksikan pola agar mempermudah dan tepat sasaran sesuai dengan Program Pemberantasan ISPA. Masyarakat pun dapat mengetahui tentang apa itu ISPA dan penyebaran penyakit ISPA di wilayah Kecamatan Kaliwungu lebih detail dan membentuk masyarakat tanggap ISPA.

Klasifikasi otomatis dengan metode Naive Bayes diterapkan pada klasifikasi untuk pencarian buku oleh Ginting dkk [8].Proses klasifikasi dilakukan dengan dua tahapan yaitu fase learning yang digunkan untuk mengetahui kelas data untuk membentuk model perkiraan dan fase testing yang terbentuk diuji dengan sebagian data lainnya untuk mengetahui akurasi dari model tersebut.Hasil dari penelitian ini adalah penggunaan Naive Bayes berhasil mencari deskripsi yang berkaitan dengan kata yang dicari oleh user dan klasifikasi dapat dilakukan dengan baik.Namun kendala dari penelitian ini adalah data yang kurang dan format yang terbatas. Penggunaan Naive Bayes juga diterapkan untuk prediksi penyakit jantung [9]. Naive Bayes akan mengklasifikasikan data tertentu ke dalam kategori yang berbeda dan juga mamperkirakan faktor resiko terkenapenyakit jantung jika tidak diketahui label dari sampel tersebut, ini juga akan membantu mahasiswa kedokteran dalam memprediksikan analisis faktor resiko agar mampu mencegah sedini mungkin hanya dengan mengubah nama file dari dataset yang telah ada diberikan.Pengembangan dari penelitian ini dapat dilakukan dengan dataset yang berbeda.Dua penelitian tersebut hanya menghasilkan data dan belum ada visualisasinya. Visualisasi untuk analisis spasial dilakukan oleh [10] untuk Membahas tentang visualisasi dari hasil kajian Isohyet dengan Thiessen mengenai jumlah curah hujan pada daerah Sub-DAS Ciesek. Dengan melakukan analisis spasial dengan metode Isohyet dan Thiessen dengan metode overlay guna mencegah daerah rawan banjir. Penelitian lain yang mengacu pada visualisasi geografis terjadi di Provinsi Nakorn Pathom [11] yang merupakan daerah pertanian 
maju. Pengembangan pengumpulan datanya menggunakan Google Maps API, yang termasuk didalamnya penggunaan peta online dan koordinat geografis dari peta. Selanjutnya dengan bantuan Google Earth akan melihat data satelit dalam resolusi yang tinggi, yang disimpan dalam berkas KML, overlay-nya dari Google Maps. Digunakan untuk membantu memantau daerah produktif pertanian.

Penelitian ini akan melakukan pengklasifikasian data penyakit ISPA di wilayah Kecamatan Kaliwungu dengan metode Naïve Bayes yang didasarkan pada jenis ISPA, tahun terkena, jenis kelamin dan gejala. Selanjutnya akan divisualisasikan ke dalam bentuk peta yang mempermudah analisis spasial guna mencegah penyebaran penyakit ISPA dan membantu Dinas Kesehatan mencapai target P2 ISPA.

\section{METODE PENELITIAN}

Di bawah ini merupakan pengolahan data dengan metode Naive Bayes :

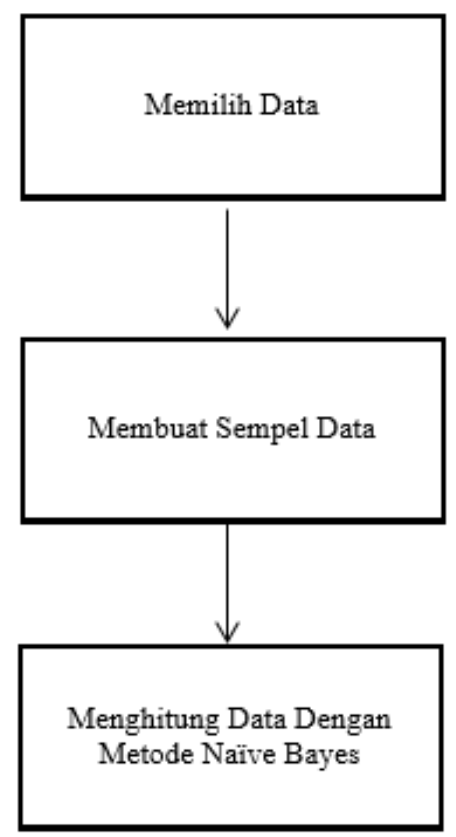

Gambar 1. Pelaksanaan Metode Naïve Bayes

Tahap perhitungan Naive Bayes Classifier adalah sebagai berikut :

1. Hitung $\mathrm{P}\left(\mathrm{X}_{\mathrm{k}} \mid \mathrm{Ci}\right)$ untuk setiap kelas $i$

2. Hitung $\mathrm{P}(\mathrm{X} \mid \mathrm{Ci})$ untuk setiap kelas:

$P(X \mid C i)=\prod_{k=1}^{n} P(x k \mid C i)$

3. Hitung $\mathrm{P}(\mathrm{X} \mid \mathrm{Ci}) * \mathrm{P}(\mathrm{Ci})$

4. Pengelompokan kelas

Tahapan visualisasi dilakukan dengan teknik overlay (tumpang tindih). Proses overlay dibagi kedalam 5 tahap, berikut ini alurnya : 


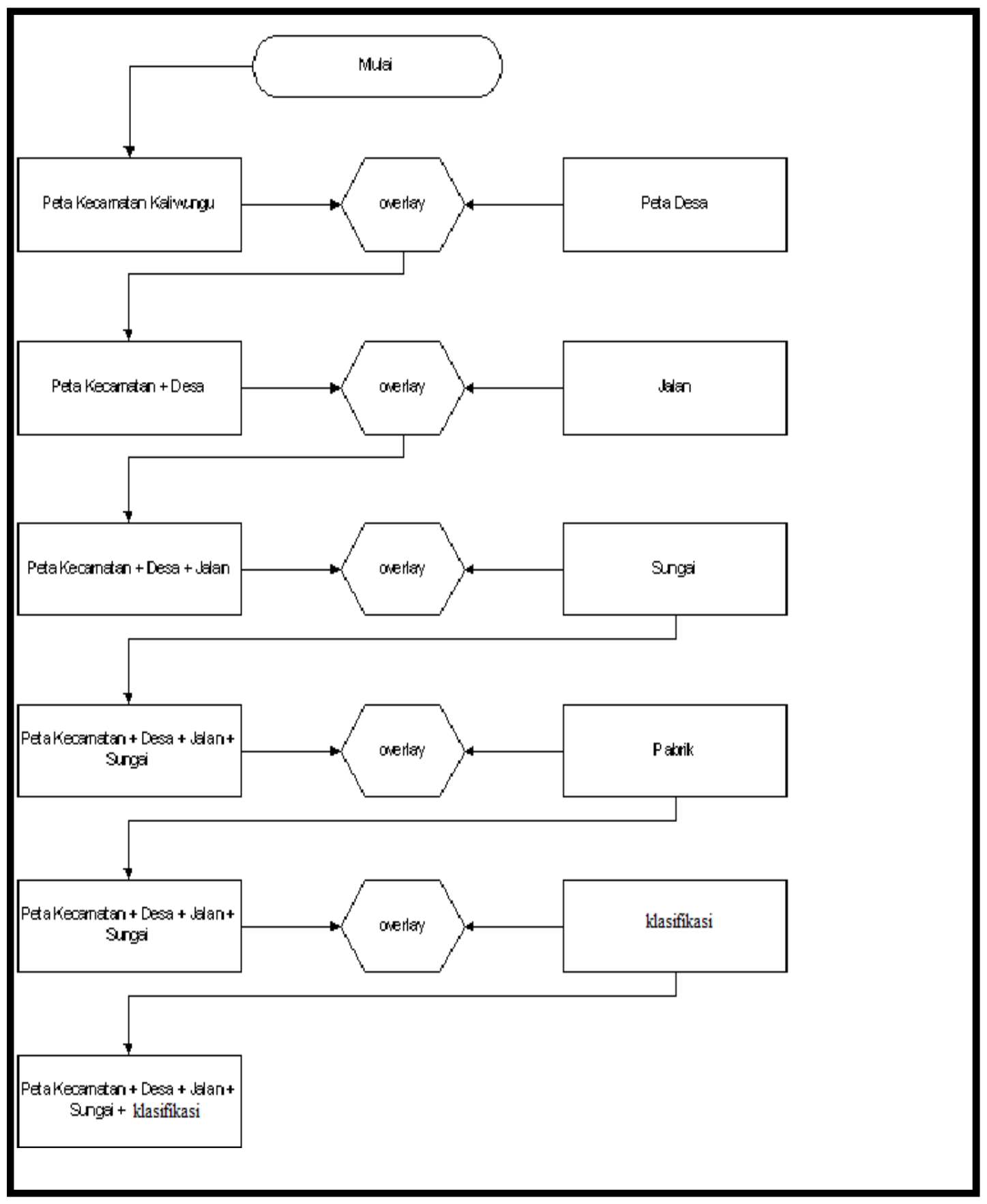

Gambar 2. Tahap Visualisasi dengan Metode Overlay

Proses overlay pertama kali dimulai dengan menggunakan peta Kecamatan Kaliwungu yang telah dibagi per daerah, dalam proses pembagian per daerah juga menggunakan teknik overlay (tumpang tindih peta). Selanjutnya, akan dihasil kanpeta Kecamatan Kaliwungu + Peta Per Desa di wilayah Kacamatan Kaliwungu, untuk kemudian diproses digabungkan dengan peta jalan raya di daerah Kecamatan Kaliwungu. Peta yang dihasilkan berupa peta Kecamatan Kaliwungu + Peta per Desa + PetaJalan Raya dan dilakukan teknik overlay lagi digabungkan 
Visualisasi Berbasis Naïve Bayes untuk Pemetaan Penyebaran Penyakit ...

dengan peta aliran sungai yang ada di wilayah Kecamatan Kaliwungu. Peta yang dihasilkan akan dioverlay lagi dengan hasil dari klasifikasi denga nmenggunakan teknik Naïve Bayes, hasil akhirnya berupa daerah aman dan daerah rawan ISPA.

\section{HASIL DAN PEMBAHASAN}

Penelitian ini menggunakan data dari UPTD Puskesmas Kaliwungu pada tahun 20132014 dengan record sebanyak 1500. Sebelum data diolah dalam rules Naive Bayes, data murni yang telah didapatkan dari UPTD Puskesmas Kaliwungu terdiri dari nama, nomer KK, dalam wilayah, luar wilayah, nomer pasien, golongan umur, jenis kelamin, alamat, dan diagnosis (jenis penyakit, status, gejalanya,kelas penyakit), tahun terkena dan obat yang ditunjukkan pada tabel 1. Sebelum data murni tersebut diolah, dilakukan proses pembersihan(data cleaning) dengan proses manual yang dimulai dengan seleksi data untuk menentukan data mana yang akan digunakan, yaitu data yang lengkap semua atributnya dan juga penghilangan atribut ganda. Selanjutnya guna memudahkan pemprosesan data dengan teknik Naive Bayes maka dilakukan praprosessing, yaitu proses pemilihan atribut. Pemilihan atribut data didasarkan pada prioritas akibat/dampak yang paling berpengaruh dalam pemprosesan data nantinya. Atribut yang telah dipilah berupa nomer pasien, umur, jenis kelamin, diagnosis, dan tahun terkena. Nomer pasien sendiri sebenenarnya tidak berpengaruh dalam pembentukan rules Naive Bayes namun digunakan sebagai pembeda agar tidak ada data ganda. Selanjutnya, karena pada diagosis berupa 3 atribut maka nantinya akan dipecah dan berdiri sendiri-sendiri sesuai dengan klasifikasinya seperti non pnumonia, pnumonia ringan dan berat dan nantinya diubah nama menjadi kelas. Proses selanjutnya yaitu pentransformasian data-data secara manual. Data akan diubah/ditransformasi dari kategorial ke numerikal (umur, jenis kelamin, data jenis penyakit, status dan gejalanya dan asal daerah) supaya memperoleh data yang lebih berkualitas sesuai standart yang ditunjukkan pada tabel 2 dan 3 .

Tabel 1. Data Murni dari UPTD Puskesmas Kaliwungu

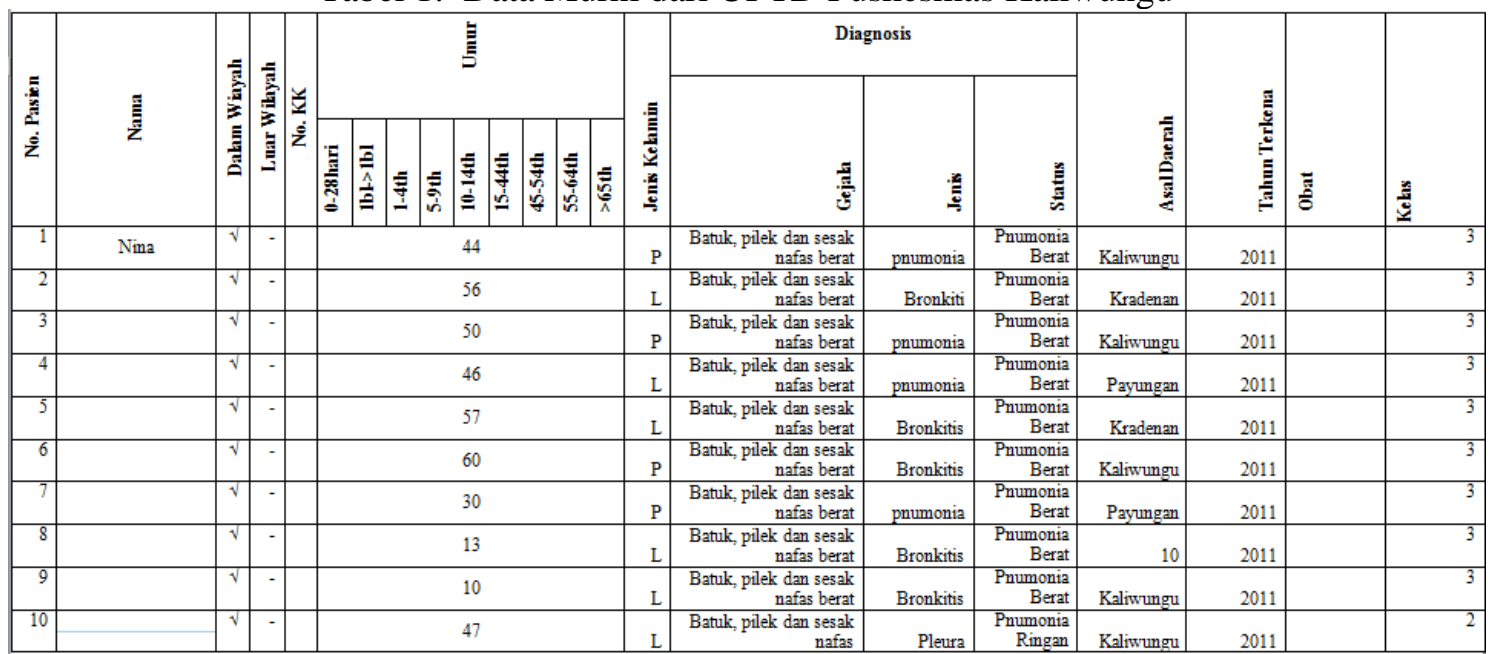


Tabel 2. Tabel sebelum ditransformasi

\begin{tabular}{|c|c|c|c|c|c|c|}
\hline $\begin{array}{c}\text { No. } \\
\text { Pasien }\end{array}$ & Umur & $\begin{array}{c}\text { Jenis } \\
\text { Kelamin }\end{array}$ & Gejala & Jenis & Status & $\begin{array}{c}\text { Asal } \\
\text { Daerah }\end{array}$ \\
\hline 13 & $\begin{array}{l}45-57 \\
\text { tahun }\end{array}$ & Perempuan & $\begin{array}{l}\text { Batuk - } \\
\text { Pilek - } \\
\text { Sesak } \\
\text { Nafas } \\
\text { Berat }\end{array}$ & Pnumonia & $\begin{array}{c}\text { Pnumonia } \\
\text { Berat }\end{array}$ & Kaliwungu \\
\hline 14 & $\begin{array}{l}55-64 \\
\text { tahun }\end{array}$ & Laki-Laki & $\begin{array}{l}\text { Batuk - } \\
\text { Pilek - } \\
\text { Sesak } \\
\text { Nafas } \\
\text { Berat }\end{array}$ & Bronkitis & $\begin{array}{c}\text { Pnumonia } \\
\text { Berat }\end{array}$ & Kradenan \\
\hline 15 & $\begin{array}{l}45-57 \\
\text { tahun }\end{array}$ & Perempuan & $\begin{array}{l}\text { Batuk - } \\
\text { Pilek - } \\
\text { Sesak } \\
\text { Nafas } \\
\text { Berat }\end{array}$ & Pnumonia & $\begin{array}{c}\text { Pnumonia } \\
\text { Berat }\end{array}$ & Kaliwungu \\
\hline 16 & $\begin{array}{l}45-57 \\
\text { tahun }\end{array}$ & Laki-Laki & $\begin{array}{c}\text { Batuk - } \\
\text { Pilek - } \\
\text { Sesak } \\
\text { Nafas } \\
\text { Berat }\end{array}$ & Pnumonia & $\begin{array}{c}\text { Pnumonia } \\
\text { Berat }\end{array}$ & Payungan \\
\hline
\end{tabular}

Tabel 3. Data yang telah ditransformasi

\begin{tabular}{|c|c|c|c|c|c|c|c|}
\hline No_Id & Umur & Jenis Kelamin & Gejala & Jenis & & Status & Asal Daerah \\
\hline 13 & & 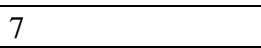 & 0 & 3 & 5 & 3 & 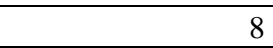 \\
\hline 14 & & 8 & 1 & 3 & 4 & 3 & 6 \\
\hline 15 & & 7 & 0 & 3 & 5 & 3 & 8 \\
\hline 16 & & 7 & 1 & 3 & 5 & 3 & 9 \\
\hline
\end{tabular}

Penelitian ini menggunakan rules dengan metode Naive Bayes pada contoh data sampel berikut sehingga menjadi :

Tabel 4. Contoh Data Sample Set Puskesmas Kaliwungu:

\begin{tabular}{ccccccc}
\hline Umur & JenisKelamin & Gejala & Jenis & Asal Daerah & TahunTerkena & Kelas \\
\hline 3 & 1 & 3 & 4 & 8 & 2011 & 3 \\
\hline 7 & 0 & 3 & 5 & 8 & 2011 & 3 \\
\hline 2 & 0 & 1 & 1 & 5 & 2011 & 1 \\
\hline 6 & 0 & 1 & 1 & 11 & 2011 & 1 \\
\hline 8 & 1 & 3 & 4 & 6 & 2011 & 3 \\
\hline 7 & 0 & 2 & 5 & 5 & 2011 & 2 \\
\hline 8 & 1 & 1 & 1 & 7 & 2011 & 1 \\
\hline 7 & 0 & 3 & 5 & 5 & 2011 & 3 \\
\hline 7 & 1 & 2 & 5 & 9 & 2011 & 3 \\
\hline
\end{tabular}

a. Perhitungan dengan Naive Bayes Classifier dengan data yang sudah memiliki kelas :

1. Hitung $\mathrm{P}\left(\mathrm{X}_{\mathrm{k}} \mid \mathrm{Ci}\right)$ untuk setiap kelas $i$ :

$$
\begin{aligned}
& \mathrm{P}\left(\text { umur="3"'|kelas="1") }=\frac{0}{3}=0\right. \\
& \mathrm{P}(\text { umur="3"||kelas="2") })=\frac{0}{3}=0 \\
& \mathrm{P}\left(\text { umur="3"'|kelas="3") }=\frac{1}{3}=0.333\right. \\
& \mathrm{P}\left(\text { jenis kelamin="1"|kelas="1") }=\frac{2}{3}=0.667\right. \\
& \mathrm{P}\left(\text { jenis kelamin="1"|kelas="2") }=\frac{0}{3}=0\right. \\
& \mathrm{P}\left(\text { jenis kelamin="1"|kelas="3") }=\frac{2}{3}=0.667\right.
\end{aligned}
$$


Visualisasi Berbasis Naïve Bayes untuk Pemetaan Penyebaran Penyakit ...

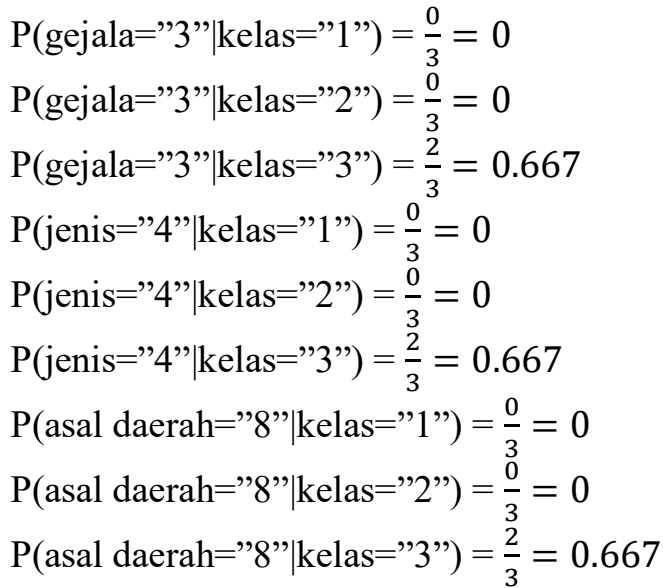

2. Hitung $\mathrm{P}(\mathrm{X} \mid \mathrm{Ci})$ untuk setiap kelas:

$P(X \mid$ kelas $1=0 \times 0,667 \times 0 \times 0 \times 0=0$

$P(X \mid$ kelas $2=0 \times 0,667 \times 0 \times 0 \times 0=0$

$P(X \mid$ kelas $3=0,333 \times 0,667 \times 0,667 \times 0,667 \times 0,333=0,032$

3. $\mathrm{P}(\mathrm{X} \mid \mathrm{Ci}) * \mathrm{P}(\mathrm{Ci})$ :

$P(X \mid$ kelas 1$) \times P($ kelas 1$)=0 \times 0,444=0$

$P(X \mid$ kelas 2$) \times P($ kelas 2$)=0 \times 0,111=0$

$P(X \mid$ kelas 3$) \times P($ kelas 3$)=0,032 \times 0,444=0,014208$

4. $\mathrm{X}$ memiliki "kelas $=3$ " karena $\mathrm{P}(\mathrm{X} \mid$ kelas 3$)$ memiliki nilai maksimum pada perhitungan tahap 3

b. Tabel Hasil Naive Bayes

Berikut ini adalah tabel hasil perhitungan Naive Bayes pada tahun 2011 :

Tabel 5. Penghitungan Naive Bayes tahun 2011

\begin{tabular}{|c|c|c|c|c|}
\hline Tahun Terkena & Asal Daerah & Kelas 1 & Kelas 2 & Kelas 3 \\
\hline \multirow{11}{*}{2011} & 1 (Siwal) & 16 & 2 & 0 \\
\hline & 2 (Kener) & 4 & 0 & 0 \\
\hline & 3 (Udanwuh) & 12 & 2 & 2 \\
\hline & 4 (Pager) & 6 & 0 & 0 \\
\hline & 5 (Papringan) & 32 & 22 & 4 \\
\hline & 6 (Kradenan) & 6 & 22 & 44 \\
\hline & 7 (Mukiran) & 46 & 10 & 10 \\
\hline & 8 (Kaliwungu) & 22 & 88 & 154 \\
\hline & 9(Payungan) & 4 & 26 & 48 \\
\hline & 10 (Jetis) & 6 & 20 & 58 \\
\hline & 11(Rogomulyo) & 98 & 18 & 18 \\
\hline
\end{tabular}

c. Perhitungan Akurasi

Berikut ini adalah perbandingan perhitungan Naive Bayes dengan data asli. Data asli ditunjukkan pada Tabel 6 .

Tabel 6. Penghitungan Naive Bayes tahun 2011

\begin{tabular}{|c|c|c|c|}
\hline Tahun & Kelas & Daerah & Jumlah \\
\hline \multirow{4}{*}{2012} & \multirow{4}{*}{2} & 1 & 3 \\
\hline & & 2 & 0 \\
\hline & & 3 & 0 \\
\hline & & 4 & 0 \\
\hline
\end{tabular}




\begin{tabular}{cc}
5 & 32 \\
\hline 6 & 62 \\
\hline 7 & 11 \\
\hline 8 & 116 \\
\hline 9 & 24 \\
\hline 10 & 34 \\
\hline 11 & 18
\end{tabular}

Perhitungan dengan Naive Bayes ditunjukkan pada Tabel 7.

Tabel 7. Penghitungan Naive Bayes tahun 2011

\begin{tabular}{|c|c|c|c|}
\hline Tahun & Kelas & Daerah & Jumlah \\
\hline \multirow{11}{*}{2012} & \multirow{11}{*}{2} & 1 & 6 \\
\hline & & 2 & 0 \\
\hline & & 3 & 0 \\
\hline & & 4 & 0 \\
\hline & & 5 & 32 \\
\hline & & 6 & 62 \\
\hline & & 7 & 22 \\
\hline & & 8 & 116 \\
\hline & & 9 & 24 \\
\hline & & 10 & 68 \\
\hline & & 11 & 18 \\
\hline
\end{tabular}

Hasil perbandingan data antara data sampel dan data hasil naive bayes :

$$
\begin{gathered}
x=\frac{\text { data asli }}{\text { data naive bayes }} \times 100 \% \\
x=\frac{300}{324} \times 100 \% \\
x=0,9259 \times 100 \% \\
x=92,59 \%
\end{gathered}
$$

Berdasarkan dari perhitungan dengan metode Naive Bayes maka kelas 1 pada tahun

\begin{tabular}{|c|c|c|c|c|}
\hline Tahun Terkena & Asal Daerah & Kelas 1 & Kelas 2 & Kelas 3 \\
\hline \multirow{11}{*}{2011} & 1 (Siwal) & 16 & 2 & 0 \\
\hline & 2 (Kener) & 4 & 0 & 0 \\
\hline & 3 (Udanwuh) & 12 & 2 & 2 \\
\hline & 4 (Pager) & 6 & 0 & 0 \\
\hline & 5 (Papringan) & 32 & 22 & 4 \\
\hline & 6 (Kradenan) & 6 & 22 & 44 \\
\hline & 7 (Mukiran) & 46 & 10 & 10 \\
\hline & 8 (Kaliwungu) & 22 & 88 & 154 \\
\hline & 9(Payungan) & 4 & 26 & 48 \\
\hline & 10 (Jetis) & 6 & 20 & 58 \\
\hline & 11(Rogomulyo) & 98 & 18 & 18 \\
\hline
\end{tabular}
2011 sebanyak 252 pasien, kelas 2 sebanyak 210 dan pada kelas 3 sebanyak 338 dengan masing-masing interval pasien per daerah bervariasi yaitu ditunjukkan pada Tabel 8 berikut.

Tabel 8. Hasil Naive Bayes pada Tahun 2011 
Visualisasi Berbasis Naïve Bayes untuk Pemetaan Penyebaran Penyakit ...

Berdasarkan dari perhitungan dengan metode Naive Bayes maka kelas 1 pada tahun 2012 sebanyak 418, kelas 2 sebanyak 300 dan kelas 3 sebanyak 526 pasien yang ditunjukkan pada Tabel 9 berikut.

Tabel 9. Hasil Naive Bayes pada Tahun 2012

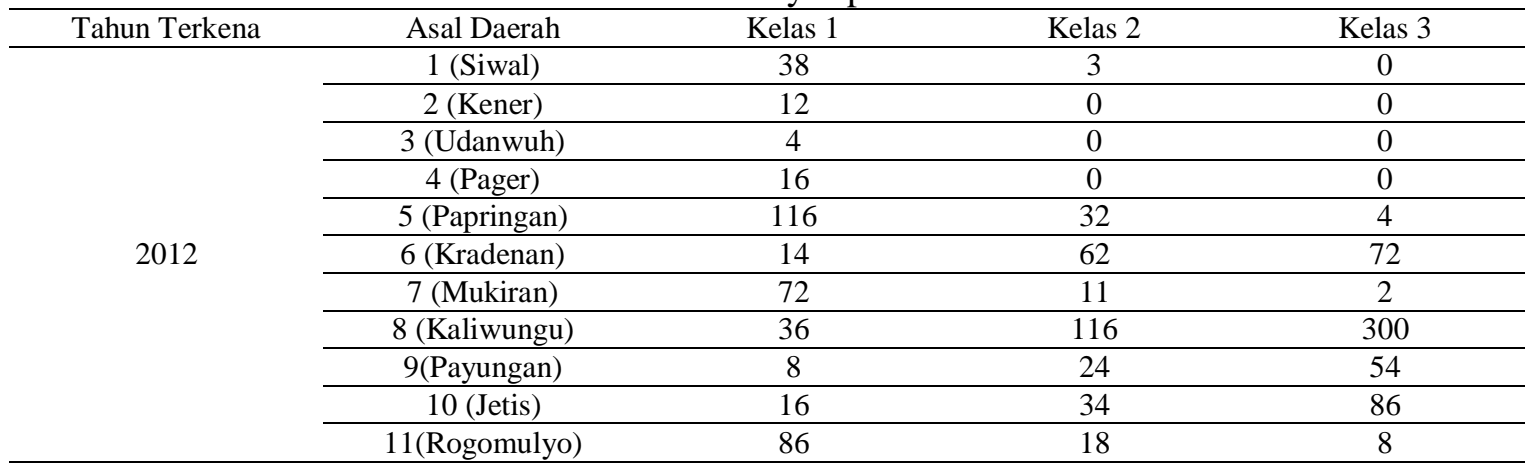

Berdasarkan dari perhitungan dengan metode Naive Bayes maka kelas 1 pada tahun 2013 sebanyak 246, kelas 2 sebanyak 216 dan kelas 3 sebanyak 446 pasien, ditunjukkan pada Tabel 10 berikut.

Tabel 10. Hasil Naive Bayes pada Tahun 2013

\begin{tabular}{|c|c|c|c|c|}
\hline Tahun Terkena & Asal Daerah & Kelas 1 & Kelas 2 & Kelas 3 \\
\hline \multirow{11}{*}{2013} & 1 (Siwal) & 6 & 0 & 0 \\
\hline & 2 (Kener) & 2 & 0 & 0 \\
\hline & 3 (Udanwuh) & 8 & 0 & 0 \\
\hline & 4 (Pager) & 4 & 0 & 0 \\
\hline & 5 (Papringan) & 34 & 8 & 2 \\
\hline & 6 (Kradenan) & 6 & 10 & 38 \\
\hline & 7 (Mukiran) & 46 & 6 & 4 \\
\hline & 8 (Kaliwungu) & 14 & 92 & 156 \\
\hline & 9(Payungan) & 10 & 34 & 120 \\
\hline & 10 (Jetis) & 14 & 60 & 122 \\
\hline & 11(Rogomulyo) & 96 & 3 & 122 \\
\hline
\end{tabular}

Hasil visualisasi menggunakan overlay berdasarkan klasifikasi di atas pada kelas 1 tahun 2011-2013 ditunjukkan pada gambar 3,4 dan 5 berikut.

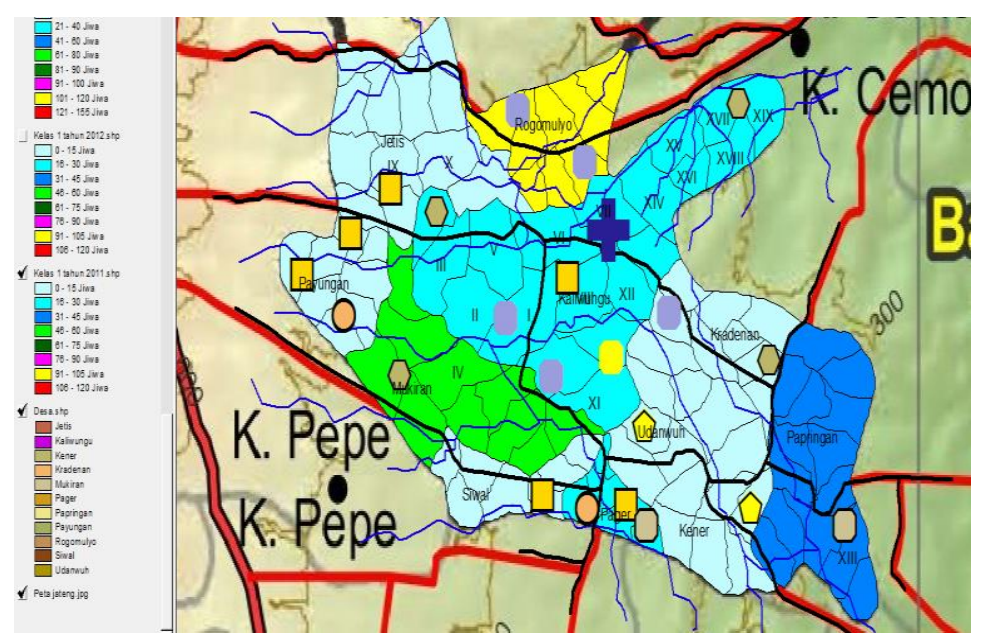

Gambar 3 Peta kelas 1 tahun 2011 


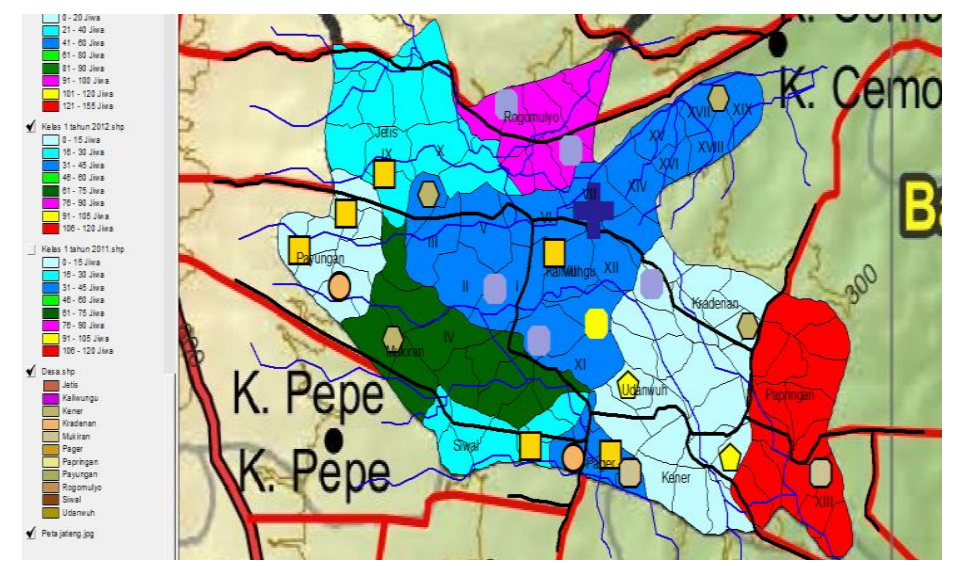

Gambar 4 Peta kelas 1 tahun 2012

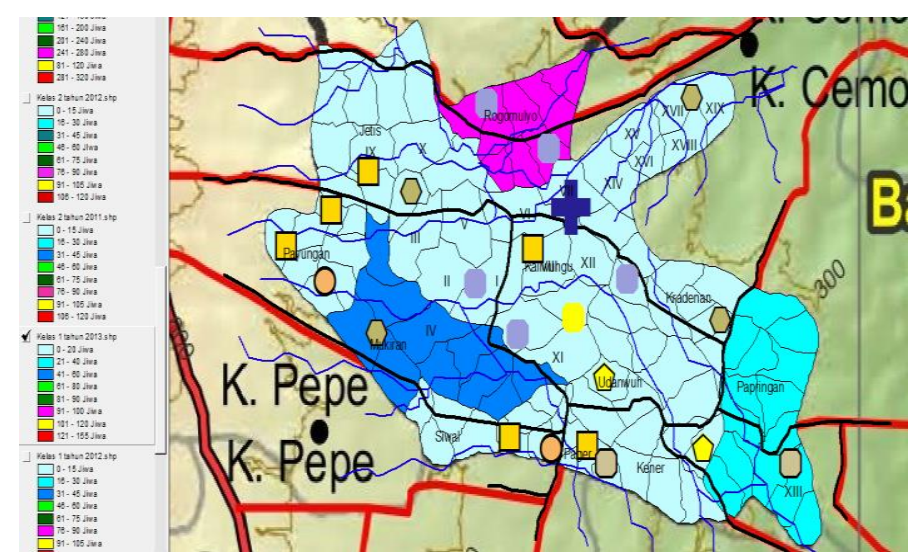

Gambar 5 Peta kelas 1 tahun 2013

\section{KESIMPULAN}

Setelah melakukan perhitungan menggunakan metode naive bayes dengan data penduduk yang terkena penyakit ISPA di Kecamatan Kaliwungu dari Target P2 yaitu : ISPA Pnumonia Berat, Pnumonia Ringan dan Non ISPA. Hasil dari perhitungan naive bayes ISPA divisualisasikan ke dalam SIG dengan metode overlay (tumpang tindih peta). Visualisasi hasil berupa Peta Kecamatan Kaliwungu dengan tingkat rawan 1-8 antara tahun 2011, 2012 dan 2013 yang berjumlah 9 peta, dengan demikian kita dapat menentukan daerah yang paling banyak terkena dan daerah yang sedikit terkena penyakit ISPA. Acuan peta berdasarkan dari faktor geografis lingkungan seperti daerah pabrik, aliran sungai, jalan raya dan pencemaran udara. Hasil penelitian adalah klasifikasi dan visualisasi data penyakit ISPA di wilayah Kecamatan Kaliwungu dengan metode Naïve Bayes yang didasarkan pada jenis ISPA, tahun terkena, jenis kelamin dan gejala, yang mempermudah analisis spasial guna mencegah penyebaran penyakit ISPA dan membantu Dinas Kesehatan mencapai target P2 ISPA.

\section{SARAN}

Penelitian ke depan dapat menambahkan data di wilayah yang lebih luas dan tahun yang lebih baru. Metode lain dapat digunakan untuk meningkatkan performa dan hasil akurasi yang 
Visualisasi Berbasis Naïve Bayes untuk Pemetaan Penyebaran Penyakit ...

didapatkan dari penelitian ini. Hasil visualisasi nantinya akan dapat ditempatkan di website sehingga mudah diakses dan pemanfaatannya dapat menjangkau wilayah yang lebih luas.

\section{DAFTAR PUSTAKA}

[1] Kementrian Kesehatan RI, 2012, Final Design Pedoman Pengendalian ISPA Tahun 2012, Kementrian Kesehatan RI, Jakarta.

[2] Suara Merdeka, 2015, Perubahan Musim, Waspadai ISPA, http://www.suaramerdeka.com/v1/index.php/read/cetak/ 2013/08/23/234408/ PerubahanMusim-Waspadai-ISPA, diakses tgl 14 Januari 2015.

[3] Haniffa, Fitri. 2014. Analisis Penatalaksanaan Pneumonia pada Balita Dengan Manajemen Terpadu Balita Sakit (MTBS) di Puskesmas Medan Denai Kota Medan Tahun 2014, Skripsi Program Studi Kesehatan Masyarakat, Universitas Sumatra Utara, Medan, 2014.

[4] Badan Pengawasan Obat dan Makanan, 2015, ISPA, http://www2.pom.go.id/public/publikasi/artikel/artikel02.html, diakses tgl 14 Januari 2015.

[5] Ikeu Nurhidayah, S.Kep., Ners, Sari Fatimah, S.Kp., M.Kes, Rakhmawati, dan Windy, S.Kp.,M.Kep. 2008. "Upaya Keluarga dalam Pencegahan dan Perawatan ISPA (Infeksi Saluran Pernapasan Akut) di Rumah pada Balita di Kecamatan Ciawi Kabupaten Tasikmalaya", Laporan Akhir Penelitian Muda(LITMUD), Universitas Padjajaran, Bandung.

[6] WHO. 2007. Pencegahan dan pengendalian infeksi saluran pernapasan akut (ISPA) yang cenderung menjadi epidemi dan pandemi di fasilitas pelayanan kesehatan. Oleh WHO, Indonesia : WHO.

[7] C A E. Permatasari. 2008. Faktor Resiko Kejadian Gejala ISPA Ringan Pada Baduta Jaya Baru Kota Depok, Fakultas Kesehatan Masyarakat Universitas Indonesia, Jakarta.

[8] Selvia Lorena Br Ginting,S.Si., dan MT, Reggy Pasya Trinanda. 2013. Penggunaan Metode Naive Bayes Classifier pada Aplikasi Perpustakaan, Jurnal Jurusan Teknik Komputer Unikom, Bandung.

[9] Dhanashree S. Medhekar,Mayur P. Bote, dan Shruti D. Deshmukh. Maret 2013. Heart Disease Prediction System using Naive Bayes, International Journal of Enhanced Research in Science Technology \& Engineering, Vol. 2 Issue 3.

[10] Mujiasih, Subekti. 2011. Pemanfaatan Data Mining Untuk Prakiraan Cuaca, Jakarta : Pusat Meteorologi Penerbangan dan Maritim.

[11] Choimeun, Ndkk. 2011. Using GIS Tool for Presenting Spatial Data: Case Study Nakorn Pathom Province. International Journal of $u$ - and e-Service, Science and Technology, Thailand. 